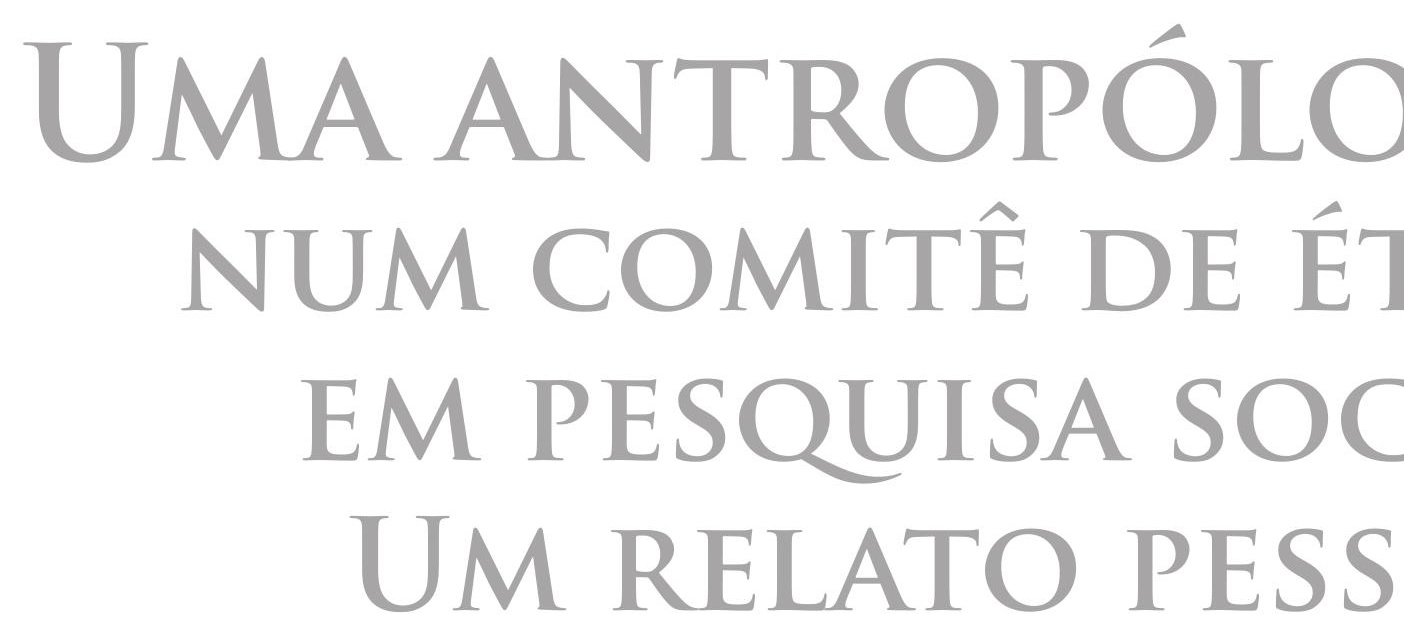




\title{
UMA ANTROPÓLOGA NUM COMITÊ DE ÉTICA EM PESQUISA SOCIAL: UM RELATO PESSOAL
}

\author{
SORAYA FLEISCHER
}

DEPARTAMENTO DE ANTROPOLOGIA, UNIVERSIDADE DE BRASÍLIA 


\title{
UMA ANTROPÓLOGA NUM COMITÊ DE ÉTICA EM PESQUI- SA SOCIAL: UM RELATO PESSOAL'
}

\section{Resumo}

A implantação de uma regulamentação ética da pesquisa científica em dezenas de países nas últimas décadas configura um dos importantes passos na proteção dos sujeitos partícipes de pesquisas. No caso brasileiro, em 1996, o Ministério da Saúde inaugurou o Conselho Nacional de Ética em Pesquisa (CONEP), bem como um sistema de revisão ética que, pouco a pouco, se popularizou pelas universidades, hospitais e secretarias de saúde do país na forma de Comitês de Ética em Pesquisa (CEP). De 2009 a 2015, como antropóloga, participei de um CEP na Universidade de Brasília, como membro titular (vice coordenadora e coordenadora) e depois membro suplente. Aqui, pretendo resgatar essa experiência e lançar uma mirada crítica ao Sistema CEP/CONEP na expectativa de contribuir para avançá-lo, ainda que esse relato esteja circunscrito especificamente àquela época da cultura de revisão ética no país.

Palavras-chave: Sistema CEP/CONEP, antropologia, ética em pesquisa.

\section{AN ANTHROPOLOGIST ON A COMMITTEE ON ETHICS IN SOCIAL RESEARCH: A PERSONAL ACCOUNT}

\begin{abstract}
The implementation of an ethical regulation of scientific research in dozens of countries in the last decades constitutes one of the important steps in the protection of the subjects involved in research. In the Brazilian case, in 1996, the Ministry of Health inaugurated the National Council for Ethics in Research (CONEP), as well as an ethical review system that gradually became popular in universities, hospitals and health secretariats in the country, in the form of Research Ethics Committees (CEP). From 2009 to 2015, as an anthropologist, I was part of a CEP at the University of Brasília, as a full member (vice-coordinator and coordinator) and later as a standby member. Here, I intend to register this ex-
\end{abstract}


perience and launch a critical look at the CEP/CONEP system in the hope of contributing to its progress, even though this report is limited specifically to that time of the ethical review culture in the country.

Key words: CEP/CONEP system, anthropology, research ethics.

\section{UNA ANTROPÓLOGA EN UN COMITÉ DE ÉTICA EN INVESTI- GACIÓN SOCIAL: UN RELATO PERSONAL}

\section{Resumen}

La implementación de una reglamentación de ética para la investigación científica en decenas de países en las últimas décadas configura un paso importante en la protección de los sujetos que participan en las investigaciones. En el caso brasilero, en 1996, el Ministerio de Salud inauguró el Consejo Nacional de Ética en Pesquisa (CONEP), como un sistema de revisión ética que, poco a poco, se popularizó en las universidades, hospitales y secretarías de salud del país a manera de Comités de Ética en Pesquisa (CEP). De 2009 a 2015, como antropóloga, participé de un CEP en la Universidad de Brasilia, como miembro titular (vice-coordinadora y coordinadora) y después como miembro suplente. Aquí pretendo rescatar esa experiencia y lanzar una mirada crítica al Sistema CEP/CONEP con la expectativa de contribuir para su avance, a pesar de que este relato esté circunscrito específicamente a aquella época de la cultura de revisión ética en el país.

Palabras clave: Sistema CEP/CONEP, antropología, ética en investigación.

Soraya Fleischer

soraya@unb.br 


\section{INTRODUÇÃO}

A implantação de uma regulamentação ética da pesquisa científica em dezenas de países nas últimas décadas configura um dos importantes passos na proteção dos sujeitos partícipes de pesquisas. No caso brasileiro, em 1996, o Ministério da Saúde inaugurou o Conselho Nacional de Ética em Pesquisa (CONEP), bem como um sistema de revisão ética que, pouco a pouco, se popularizou pelas universidades, hospitais e secretarias de saúde do país na forma de Comitês de Ética em Pesquisa (CEP). Essa nova esfera é também resultado das demandas dos movimentos sociais em saúde, do Conselho $\mathrm{Na}$ cional de Saúde, no marco da Reforma Sanitária brasileira. Nesse esteio, foram criados mecanismos de ouvidoria, controle social e também defesa das pessoas que, na condição de pacientes e enfermos, integrariam pesquisas científicas apenas mediante informação e concordância explícita nessa participação. Por isso, até hoje, nos CEPs e também na CONEP, um dos assentos é necessariamente do representante das "usuárias". ${ }^{2}$ Esse espaço se refere, historicamente, a esse início da regulamentação ética no país, quando a principal preocupação era que as pacientes do SUS não se transformassem em cobaias humanas descartáveis. Hoje, não só "usuárias do SUS" são representantes nos CEPs e na CONEP, mas pessoas da sociedade civil organizada como um todo, afinal, não apenas na área da saúde são realizadas pesquisas. Assim, é impensável ignorarmos a motivação para a criação do que é chamado de "Sistema CEP/CONEP" bem como o ganho que evoca em termos da consolidação da democracia brasileira, da discussão sobre eticidade em pesquisa, da explicitação das etapas da produção científica.

Antropólogas também têm acumulado experiências no sistema CEP/CONEP, seja como pesquisadoras que acompanham a apreciação ética de seus projetos pelos CEPs, seja como membros integrantes do sistema CEP/CONEP, por exemplo, em comitês locais ou nos grupos de trabalho dentro da CONEP. Relatos do primeiro tipo têm sido mais comumente encontrados (Porto 2010; Vieira 2010; Langdon et al, 2008), enquanto os do segundo tipo são mais raros (Diniz 2010). Sem perder de vista que um sistema como esse representa um grande ganho na consolidação do controle social na fabricação do Estado e da Ciência, esse artigo pretende ser um singelo relato de experiência que se aproxima do segundo tipo.

De 2009 a 2015, participei de um CEP na Universidade de Brasilia, como membro titular (vice coordenadora e coordenadora) e depois membro suplente. Aqui, pretendo resgatar essa experiência e lançar uma mirada crítica ao "sistema" na expectativa de contribuir para avançá-lo, ainda que reconheça que esse relato de experiência esteja circunscrito especificamente àquela época da cultura de revisão ética no país. Quero dizer, esse período reflete o entendimento de eticidade que pautava nosso trabalho a partir, principalmente, da resolução 196/96 e que, aos poucos, passava a receber influências também da nascente 466/12. A intenção aqui é adensar o conjunto 
de relatos do segundo tipo acima mencionado. O capítulo de Diniz (2010), sobre sua direta participação ao constituir, integrar e consolidar exatamente o mesmo CEP que tomo como cenário, torna-se uma referência importante para me acompanhar ao longo desse artigo. O objetivo aqui, portanto, será registrar a minha experiência de sete anos como membro desse CEP, na expectativa de refletir, de dentro e de modo crítico, sobre essa participação, esse comitê e o sistema de revisão ética. Uma contribuição mais qualitativa e pessoal será aqui encontrada, utilizando de alguns materiais como minhas "notas mentais" retrospectivas sobre esse período (Ottenberg 1990), documentos e o sítio eletrônico do referido CEP, dados a respeito dos projetos de pesquisa que tramitaram por esse CEP.

\section{HISTÓRIA DO CEP/IH}

O Comitê de Ética em Pesquisa do Instituto de Ciências Humanas (CEP/ $\mathrm{IH})$ é um dos três comitês existentes na Universidade de Brasília. O mais antigo é o da Faculdade de Ciências da Saúde (CEP/FS), seguido pelo da Faculdade de Medicina (CEP/FM). O $\mathrm{CEP} / \mathrm{IH}$ foi o primeiro comitê de ética em pesquisa especializado em pesquisa social no país. Em 2007, ele foi criado de forma independente, primeiro operando de modo informal e interno à UnB. Em 2008, ele foi registrado no sistema CEP/CONEP. Em 2011, foi aprovado um regimento interno que sistematizou seu funcionamento. Em 2015, passou a se chamar Comitê de Ética em Pesquisa em Ciências Hu- manas e Sociais (CEP/CHS), e deixou de ser sediado no Instituto de Ciências Humanas migrando para a Faculdade de Direito, também na Universidade de Brasilia. ${ }^{3}$ Como seu rebatismo e reinserção institucional aconteceram após a minha saída do Comitê, prefiro continuar me referindo ao seu nome original para, propositalmente, marcar o período histórico ao qual eu farei referência nesse artigo.

O CEP/IH nasceu como uma alternativa ao modelo hegemônico que rege o Sistema CEP/CONEP. Em 1996, foi publicado o primeiro marco regulamentador da ética em pesquisa no país. Contudo, como vários colegas já demonstraram, esta resolução (196/96), emitida pelo Ministério da Saúde, teve como norte a pesquisa biomédica, tanto em seu formato quanto em suas preocupações éticas (Victora el al 2004; Schuch e Fleischer 2010). O resultado imediato mais observado por colegas das Ciências Sociais era a extrema morosidade e, mais importante, o não entendimento de seus projetos e epistemologias por parte dos membros dos CEPs. Isto se devia também ao fato de que os CEPs mais convencionais e com mais antiguidade tendiam a ser menos equitativos em termos de representatividade de áreas que não as biomédicas. Claro que, mesmo com alguma representação, o desequilíbrio em termos de assentos impedia qualquer expressividade nos momentos de votações controversas. A reação mais comum de muitas antropólogas brasileiras nesses últimos anos tem sido, por exemplo, uma retração do sistema, evitando ao máximo ter que submeter 
seus projetos de pesquisa a CEPs. Claro, não são todas que assim decidem fazer, mas há muitos relatos nos grandes eventos acadêmicos, nas notas de rodapé das publicações e nas rodas de fofocas sobre esse movimento de retração e resistência. Como lembra Diniz, não há consenso sobre a legitimidade dos comitês para a revisão ética da pesquisa social. Algumas comunidades disciplinares defendem mecanismos próprios de regulação das boas práticas de pesquisa e, portanto, consideram desnecessária a participação de especialistas de outros campos na revisão ética de seus projetos. Há ainda quem acredite que a ética na pesquisa deve ser uma atribuição e responsabilidade de cada pesquisador, não havendo razões para questioná-lo antes da execução do seu projeto. Por outro lado, uma segunda ordem de questionamentos não reconhece autoridade moral no sistema de revisão ética vigente no país, em particular pelo viés biomédico de suas regras, práticas e operações de trabalho. Os que defendem essa posição não rejeitam a revisão ética como uma atividade coletiva e multidisciplinar, apenas não se reconhecem no modelo instituído. (2010: 189-190).

Inclusive eu, mesmo como partícipe de um CEP por tanto tempo, não submeti e continuo a não submeter todos meus projetos a este sistema, não exijo que as estudantes sob a minha orientação assim o façam, não incentivo que minhas colegas o reproduzam. Nunca submeto meus projetos de pesquisa a um CEP de modo automático e rotineiro, mas somente quando minhas interlocutoras em campo condicionam a realização de minha pesquisa à aprovação do projeto por um CEP. Nesses casos, se possível, procuro guarida no $\mathrm{CEP} / \mathrm{CHS}$, onde tenho mais esperança de que a Antropologia seja uma área melhor compreendida. Essa postura é, em primeiro lugar, ética, no sentido de respeitar os pressupostos que minhas interlocutoras elaboram para a realização de minha pesquisa, em vez de priorizar uma outra lógica, exógena, exótica e por vezes violenta com os sujeitos de pesquisa, como pode ser o sistema CEP/CONEP. Segundo, é uma postura política porque, pela minha própria experiência e também de outras colegas da área, nossos projetos não são plenamente compreendidos por muitos CEPs, especialmente se a maioria dos assentos for ocupada por profissionais de áreas que não das Humanidades. Não conhecem a Antropologia, não demonstram interesse por conhecer para melhor acolher as propostas teórico-metodológicas de um projeto que venha dessa área. E, por mais que o sistema proponha avaliar somente as "questões éticas" de um projeto de pesquisa, para nós da Antropologia, é impossível dissociar a proposta metodológica de suas repercussões éticas. Portanto, conhecer como um projeto da área vai realizar a pesquisa é fundamental para medir seu grau de lisura e eticidade. Além do mais, é política, porque considero que toda área conta com um conjunto de instrumentos específicos para avaliar a eticidade de suas pesquisadoras e não somente o sistema CEP/CONEP. Pelo menos na Antropologia, a integridade ética de nossas pesquisas 
passa por muitas instâncias para ser confirmada.

Mesmo crítica ao crescente imperativo moral do sistema CEP/CONEP no ambiente acadêmico, aí dentro permaneci porque me parece que um sistema regido apenas pelo olhar das ciências da saúde não representa a diversidade de áreas, pesquisadoras e perfis de pesquisa que temos no país. Por aqueles anos, fui inspirada pela sugestão, no mesmo caminho, feito por minhas colegas Langdon, Maluf e Tornquist que apontaram para a importância de "neles permanecer e insistir na legitimação das ciências humanas como fundamentais e essenciais na garantia de direitos humanos, e na importância de se levar para dentro dos comitês (assim como para dentro dos espaços de elaboração das políticas públicas, por exemplo) nossas reflexões e nossas críticas" (2008: 146). Assim, minha participação foi um ato de resistência, antes de tudo.

Do desconforto com esse modelo mais geral surgiu a ideia de constituir um comitê temático, mais afeito a compreender a pesquisa realizada pelas Humanidades. É nesse esteio que surgiu o CEP/IH na Universidade de Brasília. Ao contrário das pesquisas clínicas, geralmente "em seres humanos", as pesquisas sociais são "sempre com pessoas" (Cardoso de Oliveira 2004, grifos originais):

Um projeto de pesquisa social é aquele que faz uso de técnicas qualitativas de investigação e/ou que adota perspectivas analíticas das ciências sociais e humanas. (...) "Pesquisa social” será referenciada no singular para demarcar a identi- dade entre os campos, mas há uma diversidade de técnicas e métodos utilizados pelos pesquisadores nas ciências sociais e humanas. O conceito de pesquisa social deve ser entendido, portanto, como um recurso argumentativo de contraste à pesquisa biomédica. (Diniz 2010: 184)

A área das Ciências Sociais vinha desenvolvendo diferentes instâncias de discussão ética para tentar conduzir práticas justas e respeitosas junto às pessoas com quem trabalhamos. A discussão ética é historicamente familiar à Antropologia já que, desde seus primórdios, como mostra Schuch (2010), os modos como contatamos, convivemos, trocamos, retribuímos com as pessoas em nossas pesquisas sempre foram objeto de escrutínio, debate e, especialmente, crises epistemológicas severas dentro da disciplina. Tudo isso, tem contribuído para um amadurecimento endógeno da questão sobre ética em pesquisa antropológica. Assim, acho que os CEPs são mais uma - e não a única nem a mais importante esfera de discussão ética sobre a pesquisa social realizada no país.

Se o CEP/IH nasceu no marco da resolução 196/96 e, já à época, foi revendo, questionando e adequando o entendimento dessa norma, ao longo do tempo foi também sendo perpassado pelas resoluções seguintes. A resolução 466/12, que foi publicada enquanto eu ainda ali dentro atuava, e a resolução 510/16, que já surgiu depois de minha saída, foram igualmente conhecidas, estudadas e se transformaram em mote para o diálogo entre esse Comitê, sua clientela e o sistema CEP/CONEP. 
Uma das marcas desse Comitê foi justamente a relação crítica com as normas, sempre as colocando em revista, em vez de simplesmente aplicá-las, sobretudo porque não foram formuladas nem por, nem para profissionais e pesquisadoras das Ciências Sociais.

Considerando que há alguma inovação na criação e cotidiano desse CEP, sugiro que seja oportuno registrar como percebi o seu funcionamento naquele período, na expectativa de que esse quadro possa incentivar outras universidades a continuarem refletindo sobre os desdobramentos éticos das pesquisas realizadas no país e, se julgarem oportuno, estabelecerem espaços de discussão acolhedora para os projetos que não provêm das áreas biomédicas. Esse texto tem intenção muito singela: descrever o cotidiano de funcionamento deste comitê de ética em pesquisa durante o período em que ali estive inserida. Irá, primeiro, detalhar o funcionamento do Comitê àquela época e, depois, discutir os mais recorrentes tipos de "pendências" dirigidas aos projetos que nos chegavam. As "pendências" eram uma das formas mais comuns de comunicação e ruídos entre os membros do CEP e as pesquisadoras que a ele recorriam, daí constituírem uma boa oportunidade para refletir sobre a cultura da revisão ética que ali estava em curso. As pendências, termo utilizado de modo genérico pelos membros desse e de outros CEPs, bem como da CONEP, se referem a um conjunto de dúvidas, perguntas, inquietações e sugestões elaboradas pelo membro do CEP que tivesse ficado a cargo de ler o projeto de pesquisa e elaborar o parecer sobre sua eticidade e também complementadas pelos demais membros do Comitê durante a reunião de deliberação sobre o encaminhamento para o projeto em questão. As pendências eram, então, enviadas de volta à pesquisadora para que, num prazo específico, respondesse, suplementasse e, se julgasse pertinente, discordasse de modo substanciado, do parecer. Como sugiro, as pendências eram a via principal e mais qualificada de diálogo (nem sempre amistoso) entre o CEP e as pesquisadoras.

\section{O COTIDIANO DO CEP/IH}

Desde seu início, o CEP/IH foi composto por membros de várias áreas, não apenas das Ciências Humanas, seguindo o critério de multidisciplinariedade sugerido pela 196/96. À época de minha participação, o Comitê contou com professoras dos departamentos de Educação Física, Saúde Coletiva, Antropologia, Psicologia, Hotelaria, Enfermagem, Serviço Social e Sociologia. Propositalmente, os convites que dirigíamos às novas integrantes vinham de áreas que estivessem enviando projetos com maior frequência ao CEP. Isso não quer dizer que essa pesquisadora emitiria pareceres sobre esses projetos, mas ela poderia informar sobre particularidades metodológicas e éticas de sua área que fossem de desconhecimento do Comitê. A exogamia de análise orientava nosso trabalho, para evitar que professoras tivessem que emitir opiniões sobre os projetos de seus pares de Departamento e/ou Instituto. Além disso, era uma forma 
de valorizar a perspectiva de estranhamento de uma área à outra.

Desde o início, o CEP/IH nasceu eletrônico, muito diferente de suas contrapartes mais antigas (Harayama 2011: 36). Toda submissão de projeto era realizada via e-mail, optando por uma alternativa mais cômoda, célere e ecológica. Lembrando que nosso CEP começou a funcionar antes da Plataforma Brasil, que só surgiu em 2011. O CEP/IH contava com uma coordenação e uma secretaria administrativa, que trabalhavam em estreito e diário contato eletrônico. A secretária respondia a todos os correios eletrônicos que chegavam, consultando a coordenação nos casos excepcionais. Ela era a única pessoa remunerada no Comitê com o vínculo de estagiária. Até então, a universidade não havia sinalizado a possibilidade de disponibilizar alguém de seu quadro permanente para essa função. Garantir a continuidade dessa secretária, inclusive como repositório da memória institucional do Comitê, mediante vínculos precários de trabalho terceirizado e informal era, sem dúvida, um dos maiores desafios de sobrevivência do CEP/IH. Mas isto parecia ser um problema comum a outros CEPs também.

As reuniões eram mensais e, num período de duas horas, cerca de uma dezena de projetos tinha seus pareceres apresentados pelas relatoras e decididos por todas as integrantes do Comitê. Essa otimização dos encontros e do tempo só era possível porque a discussão empreendida durante a reunião era substancial, sem se ater aos detalhes burocráticos. Isso quer dizer que a secretaria administrativa do CEP/ $\mathrm{IH}$, ao receber um projeto, já identificava se o mesmo tinha perfil de pesquisa social, se faltavam documentos, etc. Só projetos com a documentação completa eram distribuídos às relatoras para que os pareceres fossem emitidos. Os membros não eram onerados com projetos incompletos nem com a tarefa de identificar os detalhes faltantes. Concentravam-se no conteúdo do projeto de pesquisa. Eles recebiam os projetos com, no mínimo, uma semana de antecedência para que pudessem chegar às reuniões com pareceres elaborados para serem discutidos coletivamente. Embora os projetos contassem com vários documentos, os pareceres deveriam ser textos concisos de duas a três páginas. $\mathrm{Na}$ reunião, a relatora lia seu parecer ou mesmo o resumia oralmente. Os demais membros poderiam ou não fazer questionamentos sobre o projeto e a avaliação proposta pela colega. Por vezes, requisitavam informações suplementares. Por vezes, ajudavam a solucionar dilemas éticos percebidos pela relatora. E chegavam à conclusão, o projeto poderia ser encaminhado para aprovação, pendências ou não aprovação. Dados sobre isso serão apresentados abaixo, mas já adiantando que, ao longo da história desse CEP, pouquíssimos foram os projetos não aprovados.

Se fossem apontadas pendências no projeto, a pesquisadora teria até uma quinzena para enviar suas respostas de volta ao Comitê. A segunda leitura do projeto retificado era feita pela mesma relatora inicial, que já o conhecia detalhadamente, e geralmente não volta- 
va ao espaço coletivo do CEP/IH. A própria relatora aceitava as respostas e complementações vindas da pesquisadora e encaminhava seu projeto para a aprovação. Quando persistiam dúvidas e/ou controvérsias, a relatora poderia não aprovar ou levar de volta ao fórum do Comitê, para deliberação. Sempre que a pesquisadora discordasse das orientações da relatora e/ou do CEP/ $\mathrm{IH}$, recomendava-se que sua posição fosse devidamente justificada à luz das particularidades do projeto e/ou de sua área acadêmica. Estes me pareciam esforços de mão dupla empreendidos no âmbito do encontro interdisciplinar.

É importante lembrar que o CEP/IH tinha por objetivo analisar somente as possíveis implicações éticas envolvendo as pesquisadoras, suas instituições e as pessoas ou as comunidades com quem se daria a investigação:

$\mathrm{O}$ CEP/IH não é um comitê de revisão metodológica, muito embora reconheça a centralidade do desenho metodológico para a revisão ética de um projeto. Não há julgamento sobre o estatuto de confiabilidade das técnicas de pesquisa propostas. O objeto de trabalho é a revisão ética de um projeto, o que exige um deslocamento do olhar sobre os métodos de pesquisa para as melhores estratégias de proteção dos participantes considerando as técnicas propostas por cada pesquisador. Há um esforço por um trabalho educativo em parceria com a comunidade de pesquisa, abandonando qualquer pretensão de controle da liberdade de pesquisa que possa acompanhar o trabalho dos comitês. O entendimento é que a revisão metodológica de cada es- tudo será feita pelas comunidades disciplinares. Ao comitê, cabe a revisão ética. (Diniz 2010: 189)

Quando alguma questão apresentada por um projeto mobilizasse o Comitê, nosso encaminhamento era para que fosse mais extensivamente desenvolvida na forma de "informativos". Objetivávamos criar textos curtos que discutissem questões mais complexas, primeiro sendo aprovado no Comitê e depois figurando no sítio eletrônico do mesmo, como orientação para a comunidade acadêmica como um todo. Um primeiro informativo sobre pesquisa com crianças em ambiente escolar foi publicado ${ }^{4}$. Outros três começaram a ser produzidos sobre o TCLE oral, as pesquisas com sociedades indígenas e a ideia de risco para a pesquisa social. Esses três assuntos já tinham, à época, direcionamentos na resolução 196/96, mas não contemplavam totalmente as especificidades de nossas áreas nas Humanidades. A ideia era que esses informativos pudessem se consolidar como orientações, precedentes ou embasamentos para futuras mudanças e aprimoramentos do sistema CEP/CONEP. Percebíamos o CEP/IH também como um espaço de produção de conhecimento:

A identidade do CEP/IH provoca os limites biomédicos dos documentos que regulamentam o sistema CEP/CONEP, cuja matriz não foi idealizada levando em igual consideração as particularidades das técnicas qualitativas de pesquisa. É neste contexto que o CEP/ IH inicia uma série de reflexões, intitulada Informativo CEP/IH. O objetivo é ampliar o diálogo sobre 
práticas de revisão ética e procedimentos interpretativos adotados pelo CEP/IH. Esses são documentos sujeitos a permanente revisão, de autoria de um dos membros do Comitê e referendada pelo colegiado antes de sua divulgação. (http:// www.cepih.org.br/informativo.htm)

Embora o CEP/IH fosse devidamente registrado na CONEP, um desafio que foi bastante relatado por diferentes pesquisadoras da UnB ou externas à comunidade acadêmica era que as instituições de saúde do Distrito Federal não reconheciam os CEPs da UnB ou de outras cidades e instituições como instâncias suficientes de apreciação ética. Na prática, um hospital da cidade, ao ser visitado por uma pesquisadora, iria requisitar uma carta de aprovação da instituição desta pesquisadora (no caso, por exemplo, a UnB), mas também do Governo do Distrito Federal e, por vezes, até do CEP do hospital em questão. Assim, uma mesma pesquisa precisaria tramitar por três comitês, o CEP de sua universidade, o CEP da secretaria de saúde e o CEP do hospital onde faria o estudo. Mas frequentemente, estas três tramitações não aconteciam simultaneamente porque um CEP não acadêmico poderia exigir que primeiramente o CEP da universidade de origem da pesquisadora se posicionasse sobre sua pesquisa. Não tramitar de modo simultâneo queria dizer, necessariamente, mais tempo transcorrido. O mais grave, a meu ver, era o hospital em questão ser um hospital universitário, situado dentro do principal campus da UnB, a fazer estas mesmas exigências à pesquisadora. Quer dizer, este hospital universi- tário, mesmo estando dentro da $\mathrm{UnB}$, não respeitava os CEPs da instituição e suas respectivas decisões sobre os projetos de pesquisa. Por vezes, para emitir o documento de "aceite institucional", o hospital exigia que a pesquisadora entregasse uma longa lista de documentos, semelhante ao que o sistema CEP/CONEP recomendava, funcionando informalmente como mais um CEP, mas formalmente não registrado na CONEP.

Portanto, pesquisadoras das áreas das humanas e não necessariamente ligadas aos hospitais, precisariam passar por vários CEPs (formais e informais) para fazer pesquisas dentro destas instituições, embora suas colegas, trabalhando como estudantes, orientandas, residentes ou profissionais de saúde, colhessem dados entre pacientes de forma corriqueira e cotidiana, sem passar pelos mesmos trâmites e exigências. Eram tratamentos diferentes mantidos sob o mesmo idioma do sistema CEP/ CONEP, sob o mesmo manto institucional da UnB. A resolução 196/96 explicava ser necessário e suficiente que o projeto de pesquisa passasse por um CEP, e não por um CEP específico ou uma sequência de CEPs, como à época era relatado por várias pesquisadoras do Distrito Federal. Não consigo deixar de pensar o quanto as não aprovações emitidas pelos CEPs do GDF estavam relacionadas a certa indisponibilidade em receber nos serviços de saúde da cidade pesquisadoras críticas aos mesmos. O sistema CEP/ CONEP, também nesse caso, poderia estar servindo para proteger, e até blindar, a gestão desses serviços ao olhar 
crítico das Humanidades ou de pesquisadoras mais distantes do mundo da saúde. Estes desafios foram reportados em outras unidades da federação. Por exemplo, Langdon, Maluf e Tornquist, ao tentarem sanar as "pendências" de um projeto que passava pelo CEP da secretaria municipal de saúde de Florianópolis/SC, ouviram de

um dos responsáveis pela questão da ética em pesquisa (...) que primeiro "seria necessário avaliar o interesse da prefeitura" nessa pesquisa, o que deixa claro o quanto as "populações" e seus direitos alvo das preocupações éticas, nem sempre são os "destinatários" das preocupações dos Comitês — são vistos como espécies de "propriedades" de seus gestores. (2008: 140)

Desde seu início, o CEP/IH optou por ser eletrônico. Não havia necessidade de sala física, apenas um escaninho para recebimento de eventual correspondência em papel. Os membros, as datas e as atas das reuniões eram divulgados no sítio eletrônico do comitê $\hat{e}^{5}$. Aí também eram encontradas uma biblioteca virtual sobre ética em pesquisa e diferentes informações para facilitar a organização dos documentos necessários para as pesquisadoras submeterem seus projetos. O sítio contava, inclusive, com tutoriais e modelos de documentos. Até 2011, o recebimento de todos os projetos foi por meio de correio eletrônico, dispensando o uso de papel ou a presença física das pesquisadoras nas dependências da universidade. Essa comunicação garantia muita agilidade para o CEP/IH tramitar os projetos, bem como economia à pesquisadora que não precisava deslocar- -se até a UnB ou imprimir várias cópias dos documentos. $\mathrm{Na}$ mesma época, como um exemplo do que acontecia de modo mais corrente no sistema CEP/ CONEP, lembro de um CEP governamental que me exigiu, ao receber meu projeto de pesquisa para análise, que eu entregasse não apenas todos os documentos impressos, carimbados e assinados, como também duas resmas de papel A4. Essa condição era justificada como uma "contraparte" infra estrutural para que a tramitação ética de meu projeto pudesse acontecer.

Depois, continuou de modo remoto, mas através da Plataforma Brasil já que, no final de 2011, a CONEP criou essa base eletrônica para a circulação de todos os projetos de pesquisa em apreciação ética no país. A partir daí, todos os projetos de pesquisa que precisassem de um aval ético deveriam fazê-lo de modo eletrônico e padronizado. Isso teve um impacto positivo geral na aceleração da tramitação dos projetos, já que ficava visível para a pesquisadora o tempo de cada etapa, como recepção, análise e divulgação do parecer. Além do que, a pesquisadora se tornava um pouco menos suscetível às idiossincrasias de cada CEP. O CEP/IH passou a não mais receber projetos para serem analisados via e-mail, como o fez desde sua criação em 2007, mas somente via a Plataforma Brasil. Mas o CEP/IH continuava disponível para a comunicação eletrônica, sobre qualquer dúvida que surgisse durante o processo de submissão.

Ainda assim, logo começamos a notar alguns problemas nessa mão forte que foi se tornando a Plataforma Brasil, 
que passava a materializar o sistema CEP/CONEP. Primeiro, tornou-se impossível a pesquisadora eleger para qual CEP desejava direcionar o seu projeto. Um CEP temático, como o $\mathrm{CEP} / \mathrm{IH}$ por exemplo, precisava poder ser escolhido pela pesquisadora da área das Humanas, justamente como estratégia para escapar da má compreensão por parte de CEPs mais biomédicos. Quero dizer, a maior parte dos assentos daquele CEP era ocupada por membros com formação nas áreas da saúde, com experiência de trabalho em serviços e instituições de saúde, com a autoridade de diagnosticar e prescrever em situações de adoecimento. Todas essas características ajudavam a naturalizar que as áreas da saúde e seus respectivos representantes fossem a fonte ideal para opinar sobre como uma pesquisa deveria acontecer. Era justamente nesse ponto que a existência do CEP/IH fazia mais sentido, ao rever e ampliar concepções arraigadas de verdade e avaliação. Segundo, com a suspensão de um dos três CEPs da UnB, àquela época, vários projetos clínicos passaram a chegar ao CEP/IH. Embora fossem devolvidos à CONEP, para que os redirecionasse a CEPs com o perfil adequado, esse procedimento atrasava a tramitação do projeto e o cronograma de pesquisa da respectiva pesquisadora. A Plataforma parecia limitar a autonomia das pesquisadoras e dos CEPs como um todo. Terceiro, as informações sobre o projeto que deviam ser inseridas na Plataforma foram previstas para um protocolo clínico de pesquisa científica. À Antropologia, falar de critérios de inclusão e exclusão de uma amostra, Classificação Internacional de Doenças, uso de placebo e washout, hipóteses, desfechos primários e secundários, retenção de amostras para armazenamento em banco, por exemplo, eram assuntos bastante exóticos. Muitas vezes, era impossível deixar os campos em branco e nós orientávamos as pesquisadoras a justificar de modo padronizado que "não se aplicava à área de pesquisa”. Talvez as colegas de outras áreas, ao receberem nossos projetos da Antropologia, também os julgassem exóticos e de difícil compreensão, já que deixavam informações em branco nos formulários da Plataforma Brasil, usavam categorias conceituais desconhecidas, relativizavam ideias caras e consolidadas para essas outras áreas.

Por outro lado, a Plataforma exigia menos documentos do que o $\mathrm{CEP} / \mathrm{IH}$ estava acostumado a pedir. À primeira vista, o CEP/IH poderia parecer mais "burocrático" e que a Plataforma estivesse chegando para facilitar a vida da pesquisadora. Mas o Comitê preferia, por exemplo, receber um documento integral e contínuo referente ao projeto de pesquisa, para que pudesse ser lido no estilo de escrita de área de origem, em vez de tentar fazer sentido nas caixinhas e categorias fragmentadas, sintéticas e espalhadas pela Plataforma Brasil. O CEP/IH também inventou outro documento a ser enviado pela pesquisadora, no campo de "Anexos" da Plataforma. Passamos a sugerir o envio da "Carta de revisão ética", em que a pesquisadora teria a chance de refletir sobre os potenciais impactos e perigos de sua pesquisa para si, para a 
comunidade onde a pesquisa aconteceria, para a universidade etc. e já se adiantar sobre as formas de contorná-los. A intenção não era burocratizar ou assoberbar ainda mais, mas contribuir para uma qualificação do processo de revisão ética, em que fosse possível contemplar as especificidades de cada projeto, pesquisadora e área científica. Estas inovações foram surgindo aos poucos, à medida que o Comitê foi aprendendo a transitar pela Plataforma - ao relatar e também submeter projetos - e percebendo as limitações do sistema. Nesse sentido, o CEP/IH produziu um tutorial e uma lista de "FAQs" para facilitar a transição das pesquisadoras pela Plataforma Brasil ${ }^{6}$. Essas foram iniciativas para traduzir, aos públicos menos familiares com a institucionalização da revisão ética no país, as ferramentas que vinham sendo lançadas pela CONEP, como softwares, resoluções e exigências. Com todas essas iniciativas, o $\mathrm{CEP} / \mathrm{IH}$ tomava para si, mesmo que não fosse uma atribuição explicitamente exigida pela $\mathrm{CO}$ NEP, o papel de suavizar e tornar menos traumática às pesquisadoras (sobretudo, às neófitas) a socialização nesta cultura da revisão ética institucionalizada.

\section{PROJETOS DE PESQUISA E PESQUI- SADORAS: A CLIENTELA DO CEP/IH}

Com o intuito de ilustrar de modo mais concreto e prático o que apresentei até aqui, nessa seção, a ideia é apresentar alguns dados sobre os projetos de pesquisa que foram analisados pelo CEP/ IH naquele período em que lá atuei, em especial no biênio de 2011-2012.
O trabalho de tabulação de dados foi realizado, à época, apenas para esse período, embora pudesse ser interessante ter mais dados, relativos a todo o tempo que atuei nesse CEP. Aqui, a aposta é que os dados sobre esse intervalo sirvam como uma amostra do trabalho realizado nesse CEP. Apresento a seguir três tabelas com, respectivamente, as áreas de origem das pesquisadoras que procuraram o $\mathrm{CEP} / \mathrm{IH}$, a classificação que seus projetos receberam e os tipos mais comuns de pendências que lhe foram dirigidas.

\begin{tabular}{|c|c|}
\hline Área & $\begin{array}{c}\text { Número de } \\
\text { projetos }\end{array}$ \\
\hline Psicologia & 55 \\
\hline Linguística, Letras e Artes & 36 \\
\hline Serviço Social & 26 \\
\hline Ciências Humanas & 20 \\
\hline Saúde Coletiva & 11 \\
\hline Ciências Sociais & 10 \\
\hline Educação & 5 \\
\hline Ciências da Saúde & 4 \\
\hline Ciências Sociais Aplicadas & 4 \\
\hline Direito & 2 \\
\hline Educação Física & 2 \\
\hline Enfermagem & 2 \\
\hline Música & 2 \\
\hline Biologia & 2 \\
\hline Arquitetura & 1 \\
\hline Ecologia & 1 \\
\hline Terapia Ocupacional & 1 \\
\hline Total & 184 \\
\hline 1 A Areas & $p e s$ \\
\hline
\end{tabular}

Tabela 1: Áreas de origem das pesquisadoras. Fonte: Arquivos do CEP/IH, 20112012

O CEP/IH recebeu projetos, sobretudo, das cinco primeiras áreas, a saber, 
Psicologia, Linguística/Letras/Artes, Serviço Social, Ciências Humanas e Saúde Coletiva. Valem alguns esclarecimentos. As Ciências Sociais Aplicadas, no caso da UnB, envolvem Administração, Economia, Ciência da Informação e Documentação, Ciências Contábeis e Atuariais. As Ciências Humanas incluem as áreas da História, Serviço
Social, Filosofia ou Geografia. As Ciências Sociais, somente a Antropologia e a Sociologia. Note-se, ao final desta Tabela, como pesquisadoras de áreas como Ciências da saúde, Biologia e Ecologia também procuravam o CEP/ $\mathrm{IH}$, indicando que várias são as áreas que também desenham projetos com metodologias qualitativas.

\begin{tabular}{|c|c|c|c|c|c|}
\hline Ano & $\begin{array}{c}\text { Total de proje- } \\
\text { tos recebidos }\end{array}$ & $\begin{array}{c}\text { Projetos } \\
\text { aprovados }\end{array}$ & $\begin{array}{c}\text { Projetos com } \\
\text { pendência }\end{array}$ & $\begin{array}{c}\text { Projetos não } \\
\text { aprovados }\end{array}$ & $\begin{array}{c}\text { Média de pro- } \\
\text { jetos recebidos } \\
\text { por mês }\end{array}$ \\
\hline 2011 & 105 & 52 & 53 & 0 & 8,75 \\
\hline 2012 & 88 & 33 & 54 & 1 & 8,80 \\
\hline
\end{tabular}

Tabela 2: Avaliação dos projetos submetidos ao CEP/IH. Fonte: Arquivos CEP/IH, 2011-2012.

Para um Comitê que tinha, em média, oito professoras como membros titulares e ativos, receber uma média de 8 a 10 projetos por mês significava que cada relatora avaliava um ou dois projetos por mês, no máximo. Esse número nos ajuda a dimensionar o tipo e quantidade de trabalho voluntário que esse CEP exigia de seus membros.

A Tabela 2 reflete o momento em que projeto deu entrada no $\mathrm{CEP} / \mathrm{IH}$ e recebeu a primeira leitura feita pela relatora indicada; mas não reflete a segunda fase, quando as respostas às pendências enviadas pela pesquisadora responsável foram analisadas pela relatora inicial. Uma próxima tabela poderia ter sido gerada, onde seria possível visualizar quantos "projetos com pendências" passaram à coluna da esquerda (o ideal almejado tanto pela pesquisadora quanto pelo CEP) ou da direita (quando as pendências não eram definitivamente respondidas a contento). Os projetos desta coluna "com pendências" ficaram, numa primeira ou mesmo numa segunda rodada de discussões no Comitê, como pendentes, e só depois de voltarem ao $\mathrm{CEP} / \mathrm{IH}$ com problemas reincidentes e/ou não respondidos é que, de fato, não receberam o aval ético do comitê e foram definidos como "não aprovados".

Nota-se que mais projetos ficavam pendentes do que aprovados na primeira reunião. A pendência, mais do que uma implicância, era entendida pelo Comitê como uma tentativa de diálogo com a pesquisadora. Ela comunicava a vontade de entender melhor o que projeto previa e evitar que fosse rapidamente classificado como "não aprovado" logo na primeira leitura. Como as "pendências" eram a realidade mais comuns enfrentada pelos projetos, vale conhecê-las melhor. Elas não só falavam do olhar emitido por um CEP temático, como também in- 
formavam sobre as principais dificuldades enfrentadas pelas pesquisadoras ao se inserirem no sistema CEP/CONEP.

A 196/96, a resolução que à época orientava o sistema de revisão ética, requisitava que os seguintes documentos fossem enviados junto ao projeto de pesquisa: 1. Carta de encaminhamento ao CEP; 2. Currículo Lattes das pesquisadoras envolvidas no projeto; 3. Folha de rosto (gerada pela Plataforma Brasil); 4. Cronograma; 5. Carta de aceite institucional onde seriam produzidos os dados; 6. Termo de consentimento livre e esclarecido; 7. Termo de autorização para utilização de imagem e som para fins de pesquisa; e 8. Termo de responsabilidade pelo uso de informações e cópias de documentos para fins de pesquisa. $\mathrm{O}$ projeto de pesquisa não era um documento exigido pela Plataforma Brasil, já que as informações referentes ao mesmo eram introduzidas aqui e ali no formulário online. Ainda assim, o CEP/IH pedia que fosse enviado, já que a leitura de um documento corrido era mais comum às relatoras das áreas das humanidades e facilitava muitíssimo a compreensão da proposta. Também pedíamos, como já explicado, a Carta de revisão ética.

No sítio eletrônico do CEP/IH, além de reproduzir essa lista de documentos, havia uma explicação sobre cada um deles, na forma de um tutorial para a pesquisadora ${ }^{7}$. Os comentários sobre cada um desses documentos foram gerados a partir das pendências mais recorrentemente encaminhadas pelo CEP/IH. O objetivo desse tutorial era ajudar as pesquisadoras a evitarem a repetição dos erros mais comuns e o retardamento da tramitação do seu projeto no sistema CEP/CONEP. A secretaria administrativa do Comitê tinha, como prioridade, triar os projetos que chegavam, evitando que aqueles com documentação incompleta seguissem às relatoras. Era a secretária que fazia a comunicação rápida com a pesquisadora nessa fase inicial, já requisitando documentos que evidentemente estivessem faltando. Por um lado, com já mencionado, isso permitia que a discussão durante as reuniões mensais do $\mathrm{CEP} / \mathrm{IH}$ pudesse se concentrar nos dilemas éticos que as relatoras identificassem nos projetos de pesquisa, em vez de checar a lista de documentação. Por outro lado, acelerava o processo de tramitação, porque o projeto de pesquisa já passava à discussão ética, evitando um ir e vir com pendência documental. A celeridade não era um requisito apenas da 196/96, mas a mais relevante expectativa das pesquisadoras em sua relação com um CEP. Ainda assim, com estratégias secretariais e a elaboração de FAQs e tutoriais, os documentos eram a principal razão das pendências: 


\begin{tabular}{|l|c|}
\hline \multicolumn{1}{|c|}{ Tipo de pendência } & Número de pendências \\
\hline $\begin{array}{l}\text { Termos (TCLE, Termo de cessão de imagem, termo de assentimento } \\
\text { para menores de idade etc.) }\end{array}$ & 319 \\
\hline Metodologia da pesquisa & 156 \\
\hline $\begin{array}{l}\text { Documentos (projeto de pesquisa, carta de encaminhamento, currícu- } \\
\text { lo do pesquisador etc.) }\end{array}$ & 63 \\
\hline Participantes da pesquisa & 60 \\
\hline Cronograma da pesquisa & 40 \\
\hline Carta de aceite institucional & 32 \\
\hline $\begin{array}{l}\text { Instrumento de coleta de dados (roteiro de entrevista, questionário } \\
\text { etc.) }\end{array}$ & 29 \\
\hline Orçamento da pesquisa & 8 \\
\hline
\end{tabular}

Tabela 3: Pendências mais comuns. Fonte: Arquivos CEP/IH, 2009-2012.

Como pode ser notado na Tabela 3, alguns projetos chegavam ao Comitê com documentos ausentes. Por um lado, essa ausência poderia ter sido proposital e justificada pela pesquisadora. Por exemplo, o projeto poderia não ter previsto o uso do TCLE por escrito, mas o consentimento para a realização da pesquisa seria oferecido pelo sujeito na forma oral e, em alguns casos, gravado em áudio ou vídeo. Nesses casos, a pesquisadora, no projeto de pesquisa ou mesmo na carta de revisão ética, deveria explicar seu planejamento metodológico.

Vale ainda comentar sobre o cronograma, as escolhas metodológicas e o TCLE. O cronograma não era avaliado em sua viabilidade prática, esta era de responsabilidade da pesquisadora. Mas o cronograma apresentado era tido, sobretudo, como demarcador do início da pesquisa. Muitas vezes, o contato com os sujeitos de pesquisa era adiantado para cumprir exigências de fontes de financiamento, bancas de qualificação, agendas de viagem da orientadora etc. Segundo a 196/96, um CEP não poderia avaliar pesquisas que já tivessem começado. Apreciar um projeto já iniciado seria, como chamávamos, "dar um cheque em branco", pois o Comitê estaria referendando algo que desconhecia como tinha sido a realização. Havia pesquisadoras que planejavam o início de seu projeto para o dia seguinte à reunião do $\mathrm{CEP} / \mathrm{IH}$ e quando houvesse atrasos, em decorrência da agenda do CEP/IH, por limitações técnicas da Plataforma Brasil ou pelo resultado ser a "pendência", o projeto estouraria o cronograma previsto e figuraria como já iniciado. Isso poderia ser facilmente alterado por sugestão do Comitê. O cronograma, portanto, era um documento que refletia os dilemas do tempo na prática científica. Os conflitos surgiam quando o tempo necessário para a tramitação por um CEP não era previsto no planejamento do cronograma da pesquisa. E o CEP acabava figurando como um "empecilho" à realização da pesquisa. Ou, pior, o "freio de mão". 
Embora estivesse bastante claro aos membros do CEP/IH que a apreciação ética era sua única tarefa, muitas vezes, as discussões se referiam aos aspectos metodológicos do projeto de pesquisa. Isso não quer dizer, necessariamente, que o CEP estivesse usurpando suas atribuições, mas entendia que escolhas metodológicas poderiam resvalar em constrangimentos éticos às partícipes da pesquisa. Quanto aos procedimentos metodológicos, portanto, os seguintes aspectos foram os mais recorrentemente notados entre as pendências: Forma de seleção das participantes; Forma de convite às participantes; Número de participantes; Local de coleta de dados; Segurança dos dados da pesquisa; Quantidade de etapas da pesquisa. Aparentemente, aos olhos de colegas antropólogas, dirigir tais perguntas a um projeto de pesquisa pode parecer preciosismo ou artificialismo, já que muitas dessas informações só seriam definidas, ao menos em pesquisas etnográficas por exemplo, ao longo da mesma e em franca negociação com as pessoas com quem se convive em campo.

Contudo, é preciso guardar o contexto em que estas pendências surgiram para que fique claro como o CEP funcionava. Deixe-me trazer alguns exemplos. Lembro-me de um projeto que visava entrevistar pessoas com o vírus HIV. A pesquisadora havia previsto visitar locais de sociabilidade LGBT para conhecer, contatar e conversar com pessoas soropositivas. A relatora desse projeto aventou que dirigir uma pergunta sobre a sorologia individual num espaço coletivo, em que possivel- mente a pessoa estaria acompanhada de outras que talvez desconhecessem seu status sorológico, poderia expor e estigmatizá-la. A forma e, sobretudo, o local da abordagem foram questionados. Outro projeto me vem à lembrança. Pretendia-se entrevistar mulheres que haviam decidido pela interrupção da gestação. O Comitê questionou como os dados dessa pesquisa seriam armazenados, já que poderiam servir como provas de infração criminal contra as interlocutoras da pesquisa, pois é sabido que no Brasil o aborto é ilegal na maioria dos casos. Aqui, a pendência centrou-se na segurança das informações. A pendência era geralmente formulada como uma pergunta ou como um pedido de esclarecimento e não como uma sugestão/orientação do que, exatamente, a pesquisadora deveria fazer para, respectivamente nos dois casos, contatar ou proteger suas interlocutoras. Formular como reflexão - e não como prescrição - era uma escolha proposital por parte do CEP/IH.

O Termo de Consentimento Livre e Esclarecido (TCLE) é um expediente relativamente novo na pesquisa social e já há muitas críticas sobre o seu uso na Antropologia (Taquette 2009; Heilborn 2004; Knauth 2004; Duarte 2004). Langdon e suas colegas lembram, por exemplo:

Como fazer com a assinatura do termo no caso de populações não letradas? Como lidar com a situação de intimidação de grupos subalternizados, temerosos diante de "formulários com palavreado difícil", como é comum entre classes populares brasileiras? Até que ponto a pesquisa antropológica pode 
ser concebida em termos de uma individualização tão absoluta de seu "sujeito de pesquisa"? (2008: 139)

$\mathrm{Na}$ Antropologia, em geral, o TCLE incomoda pela sua estrangeiridade, porque é uma forma de negociar a presença em campo, que não é própria de nossa área, que provém de outras formas de fazer pesquisa, geralmente do mundo clínico. Pela minha experiência no CEP/IH, a ausência de certas informações no TCLE poderia sugerir a maneira como as pesquisadoras percebiam os sujeitos de pesquisa. Por exemplo, recebemos TCLEs em que não havia o nome e contato da pesquisadora, o objetivo da pesquisa, o caráter voluntário da participação na mesma etc. Estas eram algumas razões de esse termo figurar como a pendência mais recorrente no CEP/IH, conforme a Tabela 3. Sugiro que talvez o TCLE incomodasse também porque explicitava e, em geral, formalizava o caráter sempre negociado das relações de poder em campo.

Embora o $\mathrm{CEP} / \mathrm{IH}$ seguisse a resolução 196/96 no sentido de esperar o envio do TCLE por parte das pesquisadoras, discutimos extensamente a não onipresença e não obrigatoriedade do termo. Não vislumbrávamos o termo como um contrato jurídico com dezenas de páginas, em que tudo que poderia acontecer ao longo da pesquisa estivesse absolutamente anunciado, previsto, controlado (Langdon et al 2008: 134). Reconhecíamos com facilidade que esse controle e previsão eram aspectos impossíveis de se garantir a priori em pesquisa social. Observamos como era bastante comum a linguagem do TCLE estar inacessível ao público da pesquisa. Era esse o caso das pesquisas que lidavam com pessoas sem letramento, com deficiência ou limitação visual ou procedentes de países ou regiões que não utilizavam o português. O Comitê sugeriu, em vários casos, que o TCLE fosse customizado ao público da pesquisa, que sua versão escrita poderia ser dispensável e que versões orais fossem planejadas, bastando que a pesquisadora fizesse uma discussão sobre essas modalidades, tornando-se mais consciente, a um só tempo, do diálogo com seus sujeitos de pesquisa e também com o tema da ética em pesquisa. Em geral, sobre o termo, o espírito de nosso trabalho era o seguinte:

Para o CEP/IH, cada percurso metodológico necessita ser analisado em suas particularidades, o que significa que não há regra pré-fixada de como deve ser conduzida uma boa entrevista de pesquisa a fim de garantir a confiabilidade ou veracidade dos dados. É possível atender à solicitação de apresentação de TCLE oral em estudos de risco mínimo ou mesmo de TCLE por escrito somente após a entrevista ter sido realizada, a fim de evitar o desconforto da negociação contratual antes do início do encontro de pesquisa. A emergência de estratégias de acolbimento à diversidade disciplinar e às particularidades metodológicas de cada projeto não altera o curso de revisão ética, cujo principal objetivo é o de proteger os direitos e interesses dos participantes de uma pesquisa. (Diniz 2010: 187-188, grifos meus)

Nessa última parte do texto, o objetivo foi qualificar as pendências sugeridas 
aos projetos que passaram pelo CEP/ IH por um certo período, numa tentativa de partir dos termos locais em que a apreciação ética acontecia dentro do $\mathrm{CEP} / \mathrm{IH}$, em vez de apenas discutir e aplicar o sistema CEP/CONEP como uma inevitável "forma de bolo". A opção nesse artigo não foi fazer análises teóricas externas ao funcionamento de um CEP nem panorâmicas em relação ao sistema CEP/CONEP como um todo, como tem sido feito com muito mais propriedade por outras colegas (Harayama 2011). A "pendência" era a forma mais usual em que o diálogo entre uma pesquisadora e o CEP acontecia. Pelo potencial de atrasar o cronograma da pesquisa, mas, sobretudo, por fazer questionamentos que talvez a pesquisadora jamais recebesse de outras instâncias pelas quais o seu projeto precisaria percorrer. As pendências tinham o potencial de facilmente se transformarem num mote de conflitos entre as duas partes. E-mails críticos, exigentes e, por vezes, desaforados foram por nós recebidos. Assim, percebo que esse CEP não se tratava de uma instância qualquer de diálogo, mas permeado por relações de poder e hierarquia claros, sobretudo porque o nosso papel poderia ser de avalizar, mas também regular e desenhar o que seria "ética em pesquisa social". Trabalhávamos com certos limites em nossas práticas de acolhimento e diálogo; ainda que estabelecer uma atmosfera de escuta cuidadosa das especificidades de cada área, de cada projeto e de cada pesquisadora fosse um objetivo cultivado a cada reunião mensal do CEP/ IH. Refletir sobre a prática das pen- dências, em especial sobre as razões pelas quais o Comitê as direcionava aos projetos, pode ajudar a dimensionar o papel e lugar que o CEP/IH ocupava, então, na realização dos projetos das pesquisadoras da UnB.

\section{CONSIDERAÇÕES FINAIS}

O Brasil apresenta um interessante quadro de apreciação ética. Por um lado, a revisão ética feita pelos comitês brasileiros não é uma prática antiga e consolidada em todas as áreas científicas, como nos EUA, onde começam nos anos 1950 (Fonseca 2015), nem tampouco é tão recente, como na França, que inaugura seus primeiros CEPs apenas no início dos anos 2000 (Fassin 2006). De certo, como dito no início desse texto, os projetos das pesquisadoras das Humanidades têm sido sistematicamente lidos e analisados de forma equivocada pelos comitês mais antigos, geralmente com perfil das áreas da saúde. Aqui, não pretendi fazer um discurso proselitista sobre o sistema CEP/CONEP nem necessariamente do $\mathrm{CEP} / \mathrm{IH}$ em específico. Participei longamente de um CEP e consigo reconhecer vários de seus limites e equívocos. Ainda assim, julgo pertinente relatar sobre o seu funcionamento durante esse período em que por lá atuei, não só para auxiliar quem, por ventura, tiver que adentrar especificamente por esse CEP, mas, sobretudo, para manter um olhar vigilante e autocrítico no sentido de insuflá-lo, sempre que possível, de um acolhimento à diversidade disciplinar tão cara à universidade e à pesquisa científica. 
Estar dentro de um CEP e refletir sobre essa experiência me ofereceu três tipos de aprendizados. Primeiro, uma proximidade com a forma com que a apreciação ética vinha acontecendo no país naquela época, por contiguidade, já que o CEP/IH era partícipe do sistema CEP/CONEP como um todo, mas sobretudo por contraste, já que vinha se esforçando por reconhecer e refletir sobre os principais entraves do sistema e por propor uma série de outras traduções, suavizações e apoios às pesquisadoras para navegarem de modo mais exitoso pelo referido sistema. Segundo, participar diretamente do CEP/ IH me permitiu ajudar nosso coletivo (tanto como CEP, quanto como Departamento de Antropologia, Instituto de Ciências Sociais e até Associação Brasileira de Antropologia) a encontrar formas mais criativas e eficientes para modificar esse sistema por dentro, em vez de ficar apenas como uma pesquisadora que, vez por outra, era obrigada a tramitar projetos por um CEP e tendia somente à crítica e insatisfação com o sistema. Terceiro, por mais que esse texto tenha se concentrado exclusivamente no período em que atuei no CEP/IH na Universidade de Brasília, cultivo a expectativa de que esse modus operandi e algumas de suas invenções e desdobramentos, aqui descritos, possam inspirar outras antropólogas e colegas das Humanidades em sua atuação atual em CEPs ao redor do país, especializados ou não na pesquisa social.

\section{NOTAS}

${ }^{1}$ Agradeço à Renata Brito, secretária do $\mathrm{CEP} / \mathrm{IH}$ à época, que colaborou na com- pilação dos dados que embasam a segunda parte do texto; à Rosana Castro que, por muito tempo, trabalhou comigo no CEP/ IH e ajudou a completar algumas referências na versão final desse texto.

2 Adoto, como uma proposta acadêmica ética, feminista e política, o plural feminino em meus textos (Fleischer 2018: 53).

${ }^{3}$ A Faculdade de Direito ofereceu melhores condições para o funcionamento desse Comitê, a saber: uma sala para sediar a sua secretaria, sala de reuniões e, mais importante, parte da carga horária de uma funcionária efetiva da universidade. Um espaço físico próprio era uma exigência antiga por parte da CONEP para o pleno funcionamento desse Comitê. Além disso, uma das professoras que compunha o colegiado desse Comitê mudou sua filiação institucional para o Departamento de Direito, facilitando, evidentemente, essas negociações e a migração. Infelizmente, não consigo avaliar, de modo mais aprofundado, as repercussões dessa nova sede porque, bem antes da mudança, já não mais atuava no Comitê.

${ }^{4}$ Este primeiro Informativo produzido pode aqui ser encontrado: http://cepih. org.br/arquivos/informativo01.pdf

${ }^{5}$ http:/ / cepih.org.br/index.htm

6 http://cepih.org.br/arquivos/tutorial_ submissao_plataforma_brasil.pdf

7 http://cepih.org.br/arquivos/cep_ih_ orientacoes_submissao.pdf

\section{REFERÊNCIAS}

Cardoso de Oliveira, L. R. 2004. Pesquisas em vs. pesquisas com seres humanos, in Antropologia e Ética: $O$ debate atual no Brasil. Editado por C. Victora, R. Oliven, M. E. Maciel e A. P. Oro, pp. 33-44. Niterói: Editora da Universidade Federal Fluminense. 
Diniz, D. 2010. A pesquisa social e os comitês de ética no Brasil,in Ética e regulamentação na pesquisa antropológica. Editado por S. Fleischer e P. Schuch, pp. 183-192. Brasilia: LetrasLivres e Editora Universidade de Brasilia.

Duarte, L. F. D. Ética de Pesquisa e 'Correção Política’ em Antropologiain $A n$ tropologia e Ética: O debate atual no Brasil. Editado por C. Victora, R. Oliven, M. E. Maciel e A. P. Oro, pp. 125-130. Niterói: Editora da Universidade Federal Fluminense.Fassin, D. 2006. The end of ethnography as collateral damage of ethical regulation?. American eEthnologist 33(4) 522-524.

Fleischer, S. 2018. Descontrolada: Uma etnografia dos problemas de pressão. São Carlos: Editora Universitária.

Fleischer, S. \& Schuch, P. 2010. Ética e regulamentação na pesquisa antropológica. Brasília: Letras Livres e Editora da UnB.

Fonseca, C. 2015. Situando os Comitês de Ética em Pesquisa: o sistema CEP (Brasil) em perspectiva. Horizontes Antropológicos 21(44) 333-369.

Harayama, R. M. 2011. Do ponto de vista do sujeito da pesquisa: evento e cultura material em um comitê de ética em pesquisa. Dissertação de Mestrado. Programa de Pós-Graduação emAntropologia, Universidade Federal de Minas Gerais, Belo Horizonte.

Heilborn, M. L. 2004. Antropologia e Saúde: Considerações éticas e conciliação multidisciplinar, in in Antropologia e Ética: O debate atual no Brasil. Editado por C. Victora, R. Oliven, M. E. Maciel e A. P. Oro, pp. 57-63. Niterói: Editora da Universidade Federal Fluminense.

Knauth, D. R. 2004. As implicações éticas da pesquisa antropológica: uma reflexão a partir do caso da Aids, in in Antropologia e Ética: O debate atual no Brasil. Editado por C. Victora, R. Oliven, M. E. Maciel e A. P.
Oro, pp. 131-136. Niterói: Editora da Universidade Federal Fluminense.

Langdon, e. J., Maluf, S., Tornquist, C. S. 2008. Ética e política na pesquisa: os métodos qualitativos e seus resultados, in Ética nas pesquisas em ciências humanas e sociais na saúde, pp. 128-147. Editado por I. Guerrieiro, M. L. S. Schmidt, F. Zicker. São Paulo: Hucitec.

Ottenberg, S. 1990. Thirty years of Fieldnotes: Changing relationships to the textin Fieldnotes: The Makings of Anthropology, pp. 139-160. Editado por R. Sanjek. Ithaca: Cornell University Press.

Porto, D. 2010. Relato de uma experiência concreta com a perspectiva das ciências da saúde: Construindo o anthropological blues, in Ética e regulamentação na pesquisa antropológica, pp. 101-126. Editado por S. Fleischer e P. Schuch. Brasília: Letras Lives e EdUnB.

Schuch, P. 2010. Comentário: Multiplicando Perspectivas e Construindo Verdades Parciais Ética e regulamentação na pesquisa antropológica, pp. 101-126. Editado por S. Fleischer e P. Schuch. Brasília: Letras Lives e EdUnB.

Taquette, S. 2009. Adolescência feminina e vulnerabilidade às DST/Aids, in Aids e juventude: gênero, classe e raça, pp. 29-40. Editado por S. R. Taquette. Rio de Janeiro: EdUERJ.

Víctora, C., Oliven, R. G., Maciel, M. E., Oro, A. P. 2004. Antropologia e Ética: o debate atual no Brasil. Niterói: Editora da Universidade Federal Fluminense.

Vieira, F. B. 2010. Desencontros e descaminhos de uma pesquisa sociológica em um hospital público, in Ética e regulamentação na pesquisa antropológica, pp. 127-140. Editado por S. Fleischer e P. Schuch. Brasília: Letras Lives e EdUnB. 